\title{
Glycosylated hemoglobin (HbA1c) levels and clinical outcomes in diabetic patients following coronary artery stenting
}

\author{
Seyed Ebrahim Kassaian ${ }^{1}$, Hamidreza Goodarzynejad ${ }^{2,7^{*}}$, Mohammad Ali Boroumand ${ }^{3}$, Mojtaba Salarifar ${ }^{1}$,

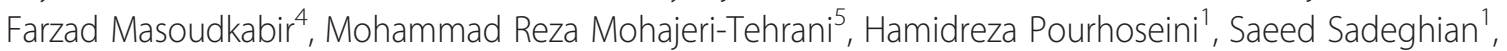 \\ Narges Ramezanpour ${ }^{2}$, Mohammad Alidoosti ${ }^{1}$, Elham Hakki ${ }^{2}$, Soheil Saadat ${ }^{6}$ and Ebrahim Nematipour ${ }^{1}$
}

\begin{abstract}
Background: Diabetes has been shown to be independent predictor of restenosis after percutaneous coronary intervention (PCI). The aim of the present study was to investigate whether a pre- and post-procedural glycaemic control in diabetic patients was related to major advance cardiovascular events (MACE) during follow up.

Methods: We evaluated 2884 consecutive patients including 2181 non-diabetic patients and 703 diabetics who underwent coronary stenting. Diabetes mellitus was defined as the fasting blood sugar concentration $\geq 126 \mathrm{mg} / \mathrm{dL}$, or the use of an oral hypoglycemic agent or insulin at the time of admission. Diabetic patients were categorized into two groups based on their mean $\mathrm{HbA1c}$ levels for three measurements (at 0,1 , and 6 months following procedure): 291 (41.4\%) diabetics with good glycaemic control (HbA1c $\leq 7 \%)$ and 412 (58.6\%) diabetics with poor glycaemic control (HbA1c > 7\%).

Results: The adjusted risk of MACE in diabetic patients with poor glycaemic control ( $\mathrm{HbA} 1 \mathrm{c}>7 \%$ ) was 2.1 times of the risk in non-diabetics (adjusted HR=2.1,95\% Cl: 1.10 to 3.95, $p=0.02$ ). However, the risk of MACE in diabetics with good glycaemic control $(\mathrm{HbA} 1 \mathrm{c} \leq 7 \%)$ was not significantly different from that of non-diabetics (adjusted $\mathrm{HR}=1.33,95 \% \mathrm{Cl}: 0.38$ to $4.68, p=0.66)$.
\end{abstract}

Conclusions: Our data suggest that there is an association between good glycaemic control to obtain $\mathrm{HbA} 1 \mathrm{c}$ levels $\leq 7 \%$ (both pre-procedural glycaemic control and post-procedural) with a better clinical outcome after PCl.

Keywords: Diabetes mellitus, Percutaneous coronary intervention, Glycaemic control, Major adverse cardiovascular events

\section{Background}

Despite recent advances in medical management and coronary revascularization, cardiovascular disease accounts for about $75 \%$ of all hospital admissions and $80 \%$ of deaths in diabetic patients [1]. Although the introduction of drug-eluting stents has reduced the rates of restenosis and clinical events after percutaneous coronary intervention (PCI), since the diabetes mellitus has been proved to be a strong risk factor for in-stent restenosis [2-4], restenosis after stent implantation

\footnotetext{
* Correspondence: hami_nag@yahoo.com

${ }^{2}$ Research Department, Tehran Heart Center, Tehran University of Medical Sciences, Tehran, Iran

${ }^{7}$ Tehran Heart Center, 1411713138, Karegar Shomali St., Jalal al-Ahmad Cross, Tehran, Iran

Full list of author information is available at the end of the article
}

remains the "Achilles' heel" of PCI [5], and patients with diabetes still have poorer clinical outcomes compared with non-diabetics [6-10].

The higher rates of restenosis in diabetic patients might be partly explained by exaggerated neointimal proliferation after stent implantation due to hyperinsulinemic state of diabetes [11]. Glycosylated hemoglobin (HbA1c) is reflective of mean ambient fasting and postprandial plasma glucose levels over the preceding 2 to 3 months $[12,13]$. There is consistent evidence that optimal glycaemic control (defined as $\mathrm{HbA1c} \leq 7 \%$ ) results in a lower incidence of microvascular complications in both type 1 and type 2 diabetes mellitus [14]. However, the corollary that optimal glycaemic control in diabetic patients would lead to a similar improvement in clinical outcome of PCI has not 
been extensively investigated. While there are conflicting data regarding the effect of preprocedural glycaemic control on outcome of PCI, there is limited data about the impact of post-procedural glycaemic control, beginning at the time of PCI and continuing afterwards, on incidence of MACEs after PCI.

In this study, we sought to investigate whether a preand post-procedural glycaemic control in diabetic patients, as reflected by mean plasma HbA1c levels prior to and 1 and 6 months after elective coronary stenting, was related to major advance cardiovascular events (MACE) during 1-year follow up.

\section{Methods}

\section{Study population}

Between October 2007 and December 2009, all consecutive patients scheduled for elective PCI at the cardiac catheterization laboratory of our center were enrolled in this prospective cohort study (Figure 1). During this period angioplasty procedure were performed in 3964 patients. Patients requiring non-elective procedures for acute coronary syndromes $(n=869)$, and patients who refused to participate in the study $(n=102)$ were excluded. The remaining 2993 patients were compatible with our selection criteria. The study protocol was approved by the ethics committee of Tehran University of Medical Sciences. Written informed consents were obtained from all participants.

\section{Coronary procedures and adjunctive antiplatelet therapy}

PCI and intracoronary stent implantation were performed according to current guidelines and using standard percutaneous techniques. Choosing the type of stent was at the discretion of the operator and each operator relied on his own judgment to assess stent expansion. All patients were on aspirin and received a 5,000-10,000 unit bolus unfractionated heparin in order to achieve an activated clotting time $>250 \mathrm{sec}$. Patients also received 300-600 mg oral clopidogrel initiated either before or in the catheterization laboratory at the discretion of the operator, and continued at the dose of $75 \mathrm{mg} /$ day for at least 1 month in bare metal and 12 months in drug eluting stents. GP IIb/IIIa antagonists were used on discretion of the operator.

\section{Biochemical analyses}

After $10 \mathrm{~h}$ overnight fasting, peripheral venous blood specimens were obtained from participants via an antecubital vein. Fasting plasma glucose (FPG) was measured by a hexokinase enzyme method. HbA1c was measured

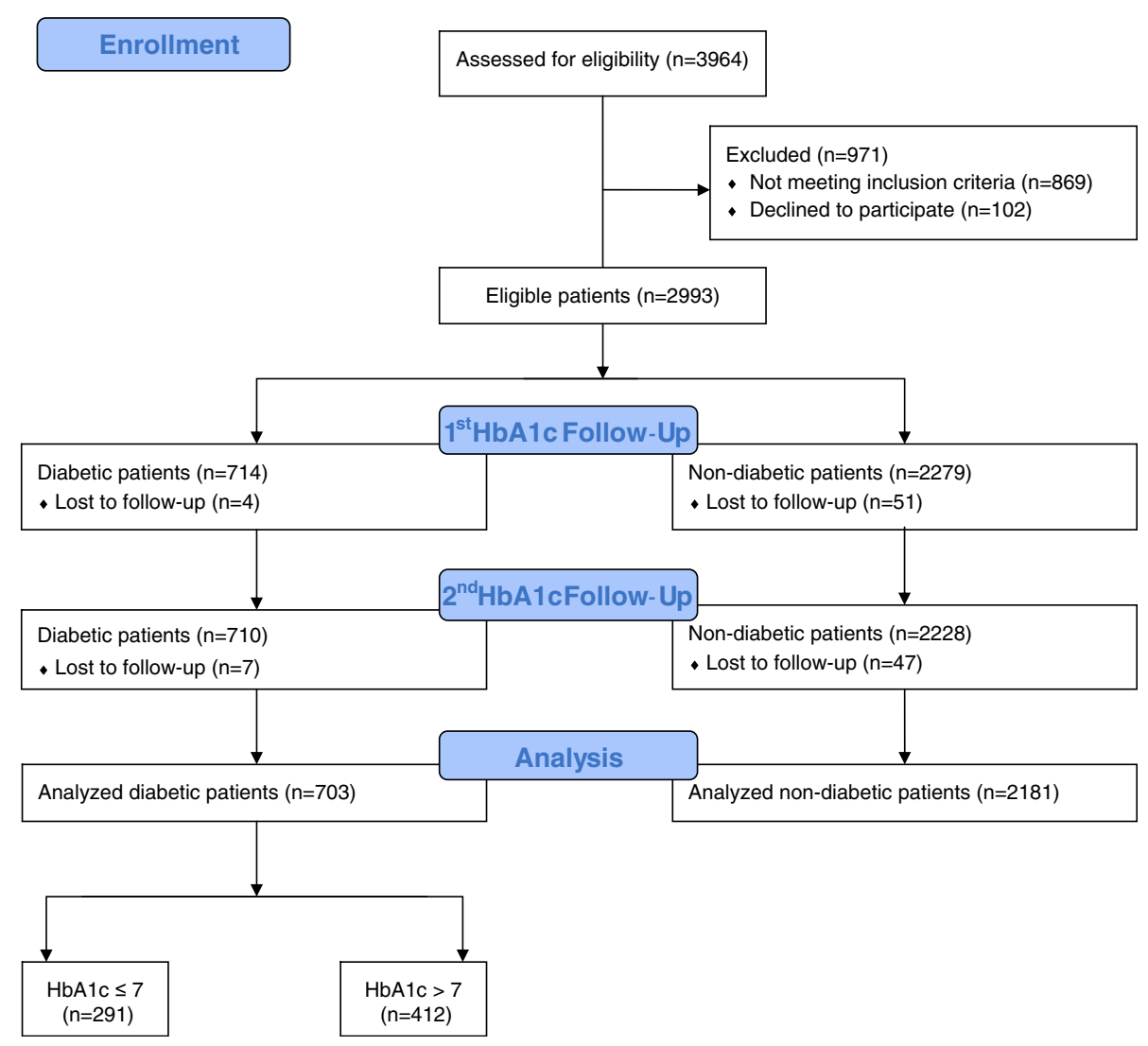

Figure 1 Flow diagram of patient recruitment and follow-up. HbA1c, glycosylated hemoglobin. 
by an immunoturbidimetric method using automatic analyzer (COBAS INTEGRA 400, Roche Diagnostics GmbH, Mannheim, Germany). Total cholesterol, HDLcholesterol, and triglycerides levels were assessed using enzyme-colorimetric tests; LDL cholesterol was estimated based on Friedewald's formula. LDL-cholesterol was not calculated if the serum triglyceride level was more than $400 \mathrm{mg} / \mathrm{dl}$. Assay performance was monitored every 50 tests, using the lipid control serum available commercial kit. Baseline blood sampling (before cardiac catheterization) for $\mathrm{HbA} 1 \mathrm{c}$ repeated at 1 and 6 months after procedure.

\section{Study endpoints and definitions}

Diabetes mellitus was defined as the fasting blood sugar concentration $\geq 126 \mathrm{mg} / \mathrm{dL}$, or the use of an oral hypoglycemic agent or insulin at the time of admission. The HbA1c levels before coronary stenting, and 1 and 6 months after the procedure was measured for diabetic patients and the mean of the 3 measurements was considered for assessing the patients' glycaemic control. "Good-control group" was defined as diabetic patients with mean HbA1c $\leq 7 \%$, "poor-control group" was defined as diabetic patients with mean HbA1c $>7 \%$. Procedural success was defined as Thrombolysis In Myocardial Infarction Flow (TIMI) grade 3 with a residual stenosis $<10 \%$. Myocardial infarction (MI) was defined as the acute-onset chest pain and/or typical modification on electrocardiogram (ST- or T-wave modification or new left bundle branch block) and an elevation of creatine kinase to $>3$ times of the upper reference limit. Target vessel revascularization (TVR) was characterized by ischemia-driven percutaneous or surgical revascularization of the treated vessel. Target lesion revascularization (TLR) by PCI was defined as treatment of a lesion in the stent or within $5 \mathrm{~mm}$ of the stent borders. The primary end point of the present study was 12-month cumulative MACE, defined as death, non-fatal MI, and the need for TVR.

\section{Patient follow-up}

The data on the early outcomes and occurrence of death, new non-fatal MI, need for CABG, subsequent need for repeat PCI in all groups were recorded. Follow up visits were scheduled at 1, 6, and 12 months after procedure conducted by clinic visits or if the patients did not attend clinics for the scheduled visits performed by telephone interviews. For the telephone follow-up interviews, at least five attempts were made to contact participants or their first-degree relatives. If telephone interviews were unsuccessful, the participants were contacted by mail using their home address.

Of a total of 2993 patients compatible with our selection criteria, 55 (51 in non-diabetic group, 3 in controlled group and 1 in uncontrolled group) patients were lost at the 1-month and 54 (47 in non-diabetic group, 4 in good-control group and 3 in poor-control group) patients at the 6-month follow-up.

Revascularization of the target vessel was considered to have been prompted by ischemia if there was evidence of angina. If the patients did not have angina symptoms, a functional stress test was performed within 12 months after the procedure to reveal silent ischemia. Repeat cardiac catheterization was performed for recurrent symptoms or objective evidence of ischemia with provocative testing. Routine angiographic follow-up was not undertaken. One-year clinical follow-up rate was 96.1\%.

\section{Statistical analysis}

The Kolmogorov-Smirnov test was applied to examine normal distribution. Continuous variables are expressed as mean \pm SD and were compared among non-diabetic, diabetic controlled, and diabetic uncontrolled groups by analysis of variance (ANOVA) followed by Scheffe's post-hoc test for pairwise comparisons. Categorical variables were compared using a chi-square test, and were presented as absolute frequencies with percentages. Event-free survival curves were constructed using the Kaplan-Meier method and compared using log-rank test. Individuals were censored at the first cardiovascular event. Cox multivariate analyses were used to determine independent predictors of MACE. Variables were entered into the model based on their statistical significance in univariable analyses (entering criterion $\mathrm{p} \leq 0.20$ ) as well as their clinical significance. To exclude the impact of HbA1c level fluctuation during the follow-up period and appropriately define the patients' group, landmark analyses were performed at the landmark times of 1-month and 6-month [15]. For all analysis, the statistical package SPSS version 15.0 for windows (SPSS Inc, Chicago, Illinois, USA) was used. All p values were 2tailed with significance defined as $p \leq 0.05$.

\section{Results}

Among 2884 patients (mean age \pm SD, $57.7 \pm 10.6$ years; $70.1 \%$ men) who entered in the analysis for assessment of the outcomes, $2181(75.6 \%)$ were non-diabetic and 703 (24.4\%) were diabetic. Of the 703 diabetic patients, 291 (41.4\%) were controlled and 412 (58.6\%) were uncontrolled. The baseline clinical and laboratory characteristics of the study patients are presented in Table 1. Diabetic patients were older and were less likely to be male as compared to non-diabetics. The prevalence of current smoking and statin-use was also lower in diabetic patients compared with non-diabetic patients; however, patients with diabetes had higher prevalence of hypertension, hyperlipidemia, and ACEIs/ARBs consumption as well as 
Table 1 Baseline clinical and pharmacological characteristics of the study patients

\begin{tabular}{|c|c|c|c|c|c|c|}
\hline & $\begin{array}{l}\text { Non-Diabetic } \\
(n=2181)\end{array}$ & $\begin{array}{l}\text { Good-control } \\
\text { DM }(n=291)\end{array}$ & $\begin{array}{l}\text { Poor-control } \\
\text { DM }(n=412)\end{array}$ & P-value ${ }^{*}$ & P-value ${ }^{\dagger}$ & P-value \\
\hline Age (year) & $57.4 \pm 10.8$ & $59.9 \pm 9.9$ & $58.0 \pm 9.8$ & $<0.0001$ & 0.27 & 0.009 \\
\hline Male sex & $1653(75.8)$ & $165(56.7)$ & $203(49.3)$ & $<0.0001$ & $<0.0001$ & 0.07 \\
\hline Hypertension & $1006(46.1)$ & $172(59.1)$ & $262(63.6)$ & $<0.0001$ & $<0.0001$ & 0.35 \\
\hline Hyperlipidemia & 1318 (61.5) & $224(77.8)$ & $328(79.6)$ & $<0.0001$ & $<0.0001$ & 0.58 \\
\hline Current smoking & $1026(47.0)$ & $79(27.1)$ & $106(25.7)$ & $<0.0001$ & $<0.0001$ & 0.86 \\
\hline Family history of CAD & $502(23.1)$ & $63(22.1)$ & 89 (21.6) & 0.77 & 0.45 & 0.78 \\
\hline $\mathrm{BMI}\left(\mathrm{kg} / \mathrm{m}^{2}\right)$ & $27.3 \pm 4.25$ & $28.3 \pm 4.1$ & $28.2 \pm 4.5$ & $<0.0001$ & $<0.0001$ & 0.85 \\
\hline WC $(\mathrm{cm})$ & $99.4 \pm 9.7$ & $101.9 \pm 9.0$ & $102.3 \pm 10.1$ & $<0.0001$ & $<0.0001$ & 0.61 \\
\hline$E F<30 \%$ & $68(4.3)$ & $7(3.5)$ & $17(5.9)$ & 0.71 & 0.18 & 0.21 \\
\hline \multicolumn{7}{|l|}{ Medications } \\
\hline Insulin & $0(0)$ & $17(6.0)$ & $69(17.0)$ & $<0.0001$ & $<0.0001$ & $<0.0001$ \\
\hline $\mathrm{OHA}$ & $0(0)$ & $84(28.9)$ & $171(41.5)$ & $<0.0001$ & $<0.0001$ & 0.001 \\
\hline ACEIs/ARBs & $1295(59.4)$ & $180(61.9)$ & $288(69.9)$ & 0.35 & $<0.0001$ & 0.04 \\
\hline Statins & $1849(84.8)$ & $255(87.6)$ & $362(87.9)$ & 0.121 & 0.06 & 0.912 \\
\hline Beta-blockers & 1915 (87.8) & $244(83.8)$ & $355(86.2)$ & 0.11 & 0.55 & 0.34 \\
\hline
\end{tabular}

Data are presented as mean \pm SD or $n(\%)$.

* Non-diabetic patients versus good-control (diabetic patients with $\mathrm{HbA1c} \leq 7 \%$ ).

† Non-diabetic patients versus poor-control (diabetic patients with $\mathrm{HbA} 1 \mathrm{c}>7 \%$ ).

\$ Good-control versus poor-control diabetic patients.

ACEls, angiotensin converting enzyme inhibitors; ARBs, angiotensin receptor blockers; BMI, body mass index; CAD, coronary artery disease; DM, diabetes mellitus;

$\mathrm{EF}$, ejection fraction; $\mathrm{OHA}$, oral hypoglyceamic agent; WC, waist circumference.

greater body mass index (BMI) and waist circumference (WC). Diabetic patients with good glycaemic control were older and less often female than uncontrolled diabetics, and less commonly treated with insulin and ACEIs/ARBs.

As seen in Table 2, Diabetic patients showed higher levels of TG and FBS. Diabetic controlled group as compared to uncontrolled group had significantly lower levels of TG and HbA1c.

The cardiac catheterization data of the study patients are summarized in Table 3. Diabetic patients had higher prevalence of 3-vessel disease and were more treated with drug-eluting stent. There were no significant differences between the diabetic and non-diabetic patients regarding the rest of clinical, laboratory and cardiac catheterization parameters. Also, no significant difference was observed between diabetic controlled and uncontrolled with respect to cardiac catheterization parameters.

During the 12-months follow-up in the entire population, 95 (3.3\%) MACEs comprised of 40 (1.4\%) TVR, 36 (1.2\%) non-fatal MI, and $19(0.6 \%)$ cardiovascular mortality were indexed. Although there was significant difference between the poor-controlled diabetic patients and nondiabetics with respect to rate of TVR (3.2\% vs. $1.1 \%$, respectively, $p=0.002$ ), the rate was similar in good-

Table 2 Serum biochemistry profile of the study patients

\begin{tabular}{|c|c|c|c|c|c|c|}
\hline & $\begin{array}{l}\text { Non-Diabetic } \\
(n=2181)\end{array}$ & $\begin{array}{l}\text { Good-control } \\
\text { DM }(n=291)\end{array}$ & $\begin{array}{l}\text { Poor-control DM } \\
(n=412)\end{array}$ & P-value ${ }^{*}$ & P-value $^{\dagger}$ & P-value \\
\hline LDL-C (mmol/l) & $2.52 \pm 1.02$ & $2.43 \pm 0.92$ & $2.51 \pm 1.15$ & 0.12 & 0.80 & 0.33 \\
\hline HDL-C (mmol/l) & $1.05 \pm 0.28$ & $1.05 \pm 0.28$ & $1.08 \pm 0.56$ & 0.95 & 0.27 & 0.36 \\
\hline $\mathrm{TCH}(\mathrm{mmol} / \mathrm{l})$ & $4.38 \pm 1.18$ & $4.28 \pm 1.16$ & $4.50 \pm 1.35$ & 0.17 & 0.10 & 0.02 \\
\hline TG $(\mathrm{mmol} / \mathrm{l})$ & $1.90 \pm 1.10$ & $1.93 \pm 1.09$ & $2.15 \pm 1.17$ & 0.68 & $<0.0001$ & 0.01 \\
\hline FPG (mmol/l) & $5.34 \pm 0.68$ & $7.07 \pm 2.14$ & $10.19 \pm 3.89$ & $<0.0001$ & $<0.0001$ & $<0.0001$ \\
\hline Mean HbA1c (\%) & - & $6.6 \pm 0.7$ & $8.8 \pm 1.3$ & - & - & $<0.0001$ \\
\hline $\mathrm{Cr}(\mu \mathrm{mol} / \mathrm{l})$ & $100.8 \pm 27.6$ & $101.3 \pm 60.8$ & $99.8 \pm 32.5$ & 0.88 & 0.58 & 0.68 \\
\hline
\end{tabular}

Data are presented as mean \pm SD.

* Non-diabetic patients versus good-control (diabetic patients with $\mathrm{HbA} 1 \mathrm{c} \leq 7 \%$ ).

† Non-diabetic patients versus poor-control (diabetic patients with $\mathrm{HbA1c}>7 \%$ ).

+ Good-control versus poor-control diabetic patients.

FPG, fasting plasma glucose; HDL-C, high-density lipoprotein cholesterol; LDL-C, low-density lipoprotein cholesterol; TCH, total cholesterol; TG, triglycerides; Cr, creatinine. 
Table 3 Cardiac catheterization data

\begin{tabular}{|c|c|c|c|c|c|c|}
\hline & $\begin{array}{l}\text { Non-Diabetic } \\
(n=2181)\end{array}$ & $\begin{array}{l}\text { Good-control DM } \\
(n=291)\end{array}$ & $\begin{array}{l}\text { Poor-control DM } \\
(n=412)\end{array}$ & P-value & P-value $^{\dagger}$ & P-value \\
\hline Type C lesion & $1458(66.9)$ & $203(69.8)$ & $280(68.0)$ & 0.33 & 0.69 & 0.62 \\
\hline СTO & $78(3.6)$ & $6(2.1)$ & $11(2.7)$ & 0.23 & 0.46 & 0.63 \\
\hline 3-vessel disease & $358(16.8)$ & $57(20.2)$ & $102(25.1)$ & 0.18 & $<0.0001$ & 0.12 \\
\hline $\mathrm{RVD}<3 \mathrm{~mm}$ & $1092(50.1)$ & $165(56.7)$ & $236(57.3)$ & 0.04 & 0.006 & 0.88 \\
\hline $\mathrm{SSL}>30 \mathrm{~mm}$ & $896(41.1)$ & $128(44.0)$ & $174(42.2)$ & 0.35 & 0.66 & 0.70 \\
\hline$C R$ & $1312(60.2)$ & $164(56.4)$ & $213(51.7)$ & 0.21 & 0.001 & 0.22 \\
\hline Drug-eluting stent & $1159(54.6)$ & $192(67.1)$ & $272(66.8)$ & $<0.0001$ & $<0.0001$ & 0.86 \\
\hline Number of stents & $1.3 \pm 0.6$ & $1.3 \pm 0.6$ & $1.3 \pm 0.5$ & 0.33 & 0.41 & 0.81 \\
\hline
\end{tabular}

Data are presented as mean \pm SD or $\mathrm{n}(\%)$.

* Non-diabetic patients versus good-control (diabetic patients with $\mathrm{HbA} 1 \mathrm{c} \leq 7 \%$ ).

† Non-diabetic patients versus poor-control (diabetic patients with $\mathrm{HbA} 1 \mathrm{c}>7 \%$ ).

+ Good-control versus poor-control diabetic patients.

$\mathrm{CR}$, complete revascularization CTO, chronic total occlusion; RVD, reference vessel diameter; SSL, sum of the stents' length.

controlled diabetics and non-diabetics (1.4\% vs. $1.1 \%$, $p=0.54)$. There were no statistically significant differences among the groups with respect to non-fatal MI, cardiovascular mortality, in-hospital MACEs and total-MACEs (Table 4). Figure 2 demonstrates freedom-from-MACE survival curves in the three groups of non-diabetics, goodcontrolled diabetics, and poor-controlled diabetics.

Table 5 presents uni- and multi-variable Cox regression analysis for predictors of MACE. After adjustment for potential confounders, the risk of MACE in diabetic uncontrolled patients (HbA1c > 7\%) was 2.1 times of the risk in non-diabetic patients (adjusted $\mathrm{HR}=2.09$; $95 \%$ CI, 1.10 to 3.95; $p=0.02$ ). The confounders included age, sex, hypertension, hyperlipidemia, current smoking, waist circumference, insulin therapy, ACEIs/ARBs use, statin use, 3-vessel disease, and complete revascularization. However, the risk of MACE in diabetic patients with good glycaemic control (HbA1c $\leq 7 \%)$ was not significantly different from that of non-diabetic patients (adjusted HR $=1.48 ; 95 \% \mathrm{CI}, 0.68$ to $3.21 ; p=0.32$ ). Figure 3 shows freedom from MACE curves in the three groups after adjustment for potential confounders.

We defined the patients' group based on the average of 3-times measurements of HbA1c levels, before PCI and 1 and 6 months after PCI. However, a total of 11 diabetic patients were lost to follow-up by 6 months of follow-up. Furthermore, HbA1c level fluctuated around $7.0 \%$ over time leading to crossing over between goodcontrol and poor-control group classifications. In order to exclude the impact of HbA1c level fluctuation around $7.0 \%$ during the follow-up period and appropriately define the patients' group, we employed 1-month and 6month landmark analyses to examine the association of post-procedural glycemic control and 1-year clinical MACE of diabetic patients undergoing PCI at the landmark times. The results are summarized in Table 6.

Table 4 Follow-up data

\begin{tabular}{|c|c|c|c|c|c|c|}
\hline & $\begin{array}{l}\text { Non-Diabetic } \\
(n=2181)\end{array}$ & $\begin{array}{l}\text { Good-control DM } \\
(n=291)\end{array}$ & $\begin{array}{l}\text { Poor-control DM } \\
(n=412)\end{array}$ & P-value ${ }^{*}$ & P-value ${ }^{\dagger}$ & P-value \\
\hline Total MACE & $65(3.0)$ & $9(3.1)$ & $21(5.1)$ & 0.85 & 0.09 & 0.33 \\
\hline In-hospital MACE & $27(1.2)$ & $3(1.0)$ & $3(0.7)$ & 1.00 & 0.79 & 0.70 \\
\hline TVR & $23(1.1)$ & $4(1.4)$ & $13(3.2)$ & 0.55 & 0.002 & 0.14 \\
\hline TLR & $9(0.4)$ & $3(1.0)$ & $4(1.0)$ & 0.16 & 0.13 & 1.00 \\
\hline CABG & $10(0.4)$ & $0(0)$ & $6(1.4)$ & 0.62 & 0.03 & 0.04 \\
\hline Non-fatal MI & $26(1.1)$ & $4(1.4)$ & $6(1.4)$ & 0.77 & 0.62 & 1.00 \\
\hline All-cause mortality & $25(1.1)$ & $1(0.3)$ & $4(1.0)$ & 0.35 & 1.00 & 0.41 \\
\hline Cardiac death & $16(0.7)$ & $1(0.3)$ & $2(0.5)$ & 0.71 & 1.00 & 1.00 \\
\hline Non-cardiac death & $9(0.4)$ & $0(0)$ & $2(0.5)$ & 0.61 & 0.69 & 0.51 \\
\hline
\end{tabular}

Data are presented as $\mathrm{n}(\%)$.

* Non-diabetic patients versus good-control (diabetic patients with $\mathrm{HbA} 1 \mathrm{c} \leq 7 \%$ ).

† Non-diabetic patients versus poor-control (diabetic patients with $\mathrm{HbA1c}>7 \%$ ).

$\$$ Good-control versus poor-control diabetic patients.

CABG, coronary artery bypass grafting surgery; MACE, major adverse cardiovascular events; MI, myocardial infarction; TLR, target lesion revascularization; TVR, target vessel revascularization. 


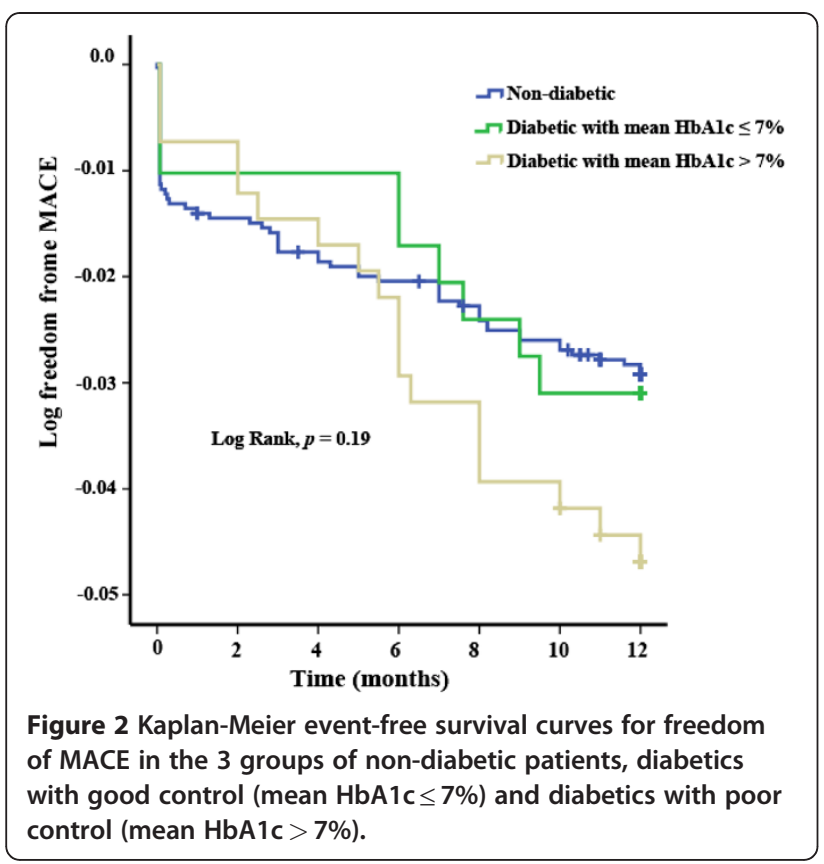

\section{Discussion}

In-stent restenosis (ISR) is mainly caused by the effects of vascular smooth muscle cell proliferation (neointimal hyperplasia) and migration. As part of mechanical injury response, immediately after stent placement, endothelium damage and the deposition of a layer of platelets and fibrin occur at the site of injury [16]. ISR also occurs lately over several months at the location around stent struts by a chronic inflammatory phase. Neointima increases up to three months after stenting, with little change to six months, and a gradual decrease thereafter [17]. Thus, the time frame of first 6 months after stent implantation was used in this study as follow-up to look at glycemic control.

An "exaggerated" vascular proliferation is observed in patients with diabetes mellitus. In diabetic animals, hyperinsulinemia rather than hyperglycemia per se, appears to be important in determining the exaggerated neointimal hyperplasia after balloon angioplasty [18]. In order to assess this topic in human, we analyzed for the effect of the post-procedural glycaemic control in the first six months after PCI on occurrence of MACE.

The main finding of our study was that glyceamic control to be significantly associated with 1-year outcome in diabetic patients undergoing elective PCI with stent implantation. We observed that diabetics with poor glycaemic control are at 2.1 times more risk of developing MACE while good-controlled diabetics showed rates of adverse clinical events comparable to those of nondiabetic patients. The higher MACE rate in the poorcontrol group was mostly driven by a higher rate of TVR.

Our findings are in agreement with several previous studies reporting increased rates of MACE following PCI

Table 5 Cox regression analysis for predictors of major adverse cardiovascular events at 12 months

\begin{tabular}{|c|c|c|c|c|c|c|}
\hline & \multicolumn{3}{|c|}{ Univariable analysis } & \multicolumn{3}{|c|}{ Multivariable analysis } \\
\hline & Crude HR & $95 \% \mathrm{Cl}$ & $P$ & Adjusted HR & $95 \% \mathrm{Cl}$ & $P$ \\
\hline Age (year) & 1.01 & 0.99 to 1.03 & 0.15 & 1.01 & 0.98 to 1.03 & 0.53 \\
\hline Male sex & 1.14 & 0.72 to 1.83 & 0.57 & 1.80 & 0.96 to 3.38 & 0.07 \\
\hline Hypertension & 1.02 & 0.68 to 1.53 & 0.92 & 0.99 & 0.60 to 1.65 & 0.98 \\
\hline Hyperlipidemia & 0.86 & 0.56 to 1.31 & 0.48 & 0.99 & 0.59 to 1.65 & 0.97 \\
\hline Current smoking & 0.65 & 0.42 to 1.00 & 0.06 & 0.60 & 0.35 to 1.03 & 0.07 \\
\hline Waist circumference & 0.98 & 0.95 to 1.00 & 0.04 & 0.97 & 0.95 to 1.00 & 0.03 \\
\hline Insulin & 1.82 & 0.74 to 4.47 & 0.19 & 1.09 & 0.32 to 3.73 & 0.89 \\
\hline ACEls/ARBs use & 1.12 & 0.73 to 1.70 & 0.61 & 0.97 & 0.59 to 1.59 & 0.44 \\
\hline Statin use & 0.91 & 0.52 to 1.62 & 0.76 & 0.81 & 0.42 to 1.56 & 0.53 \\
\hline 3-vessel disease & 1.35 & 0.83 to 2.20 & 0.23 & 1.15 & 0.61 to 2.12 & 0.67 \\
\hline Drug-eluting stent & 0.68 & 0.45 to 1.03 & 0.07 & 0.54 & 0.33 to 0.87 & 0.01 \\
\hline$C R$ & 0.63 & 0.41 to 0.96 & 0.03 & 0.75 & 0.43 to 1.29 & 0.30 \\
\hline \multicolumn{7}{|l|}{ Group } \\
\hline Non-Diabetics & $1^{*}$ & - & - & $1^{*}$ & - & - \\
\hline Good-control diabetics ${ }^{1}$ & 1.06 & 0.53 to 2.12 & 0.88 & 1.48 & 0.68 to 3.21 & 0.32 \\
\hline Poor-control diabetics ${ }^{2}$ & 1.59 & 0.96 to 2.67 & 0.07 & 2.09 & 1.10 to 3.95 & 0.02 \\
\hline
\end{tabular}

* Reference category.

ACEls, angiotensin converting enzyme inhibitors; $A R B s$, angiotensin receptor blockers; $\mathrm{Cl}$, confidence interval; $\mathrm{HR}$, hazard ratio; WC, waist circumference; $C R$, complete revascularization.

${ }^{1}$ Diabetic patient with $\mathrm{HbA} 1 \mathrm{c} \leq 7 \%$.

${ }^{2}$ Diabetic patient with $\mathrm{HbA} 1 \mathrm{c}>7 \%$. 


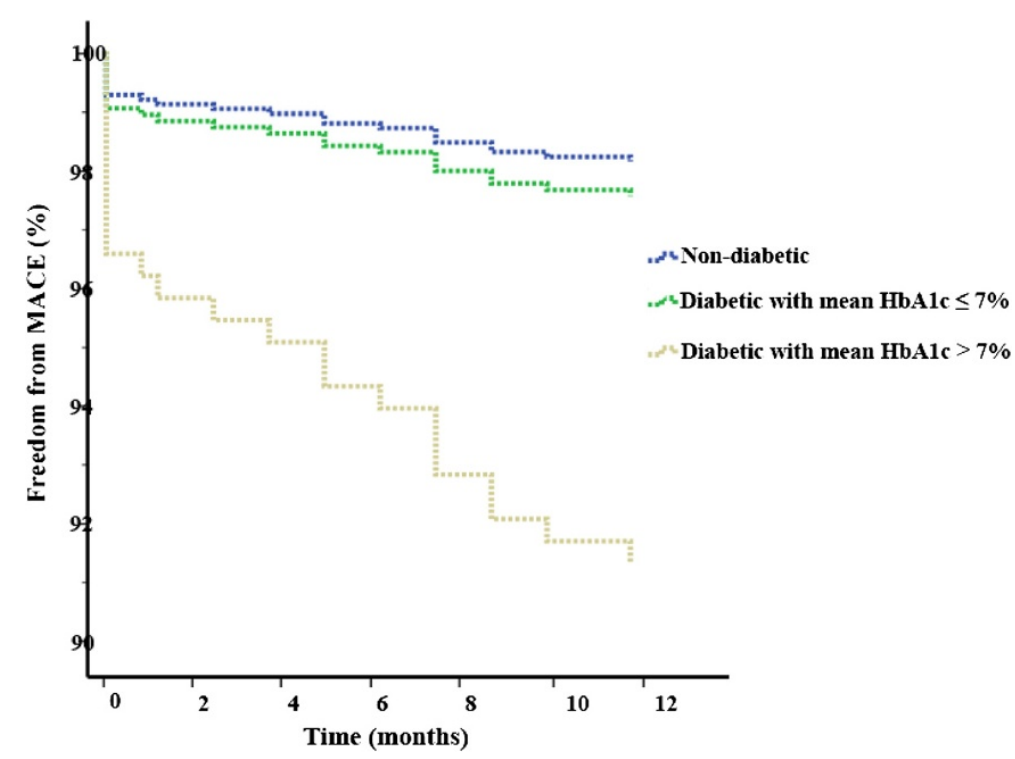

Figure 3 Cox-adjusted event-free survival curves for freedom of MACE in the 3 groups after adjustment for potential confounders including age, sex, hypertension, hyperlipidemia, current smoking, waist circumference, insulin therapy, ACEls/ARBs use, statin use, and 3-vessel disease.

Table 6 Multivariable Cox regression model for detecting the independent effect of post-procedural diabetic control on major adverse cardiovascular events (MACE) at 12 months

\begin{tabular}{|c|c|c|c|}
\hline \multirow{2}{*}{$\overline{\text { At Baseline }}$} & \multicolumn{3}{|c|}{ Odds ratio $95 \%$ confidence interval $P$ value } \\
\hline & & & \\
\hline $\begin{array}{l}\text { Non-diabetics } \\
(\mathrm{n}=2181)\end{array}$ & $1^{*}$ & - & - \\
\hline $\begin{array}{l}\text { Good-control diabetics }{ }^{1} \\
(\mathrm{n}=291)\end{array}$ & 1.54 & 0.74 to 3.19 & 0.250 \\
\hline $\begin{array}{l}\text { Poor-control diabetics }{ }^{2} \\
(n=412)\end{array}$ & 1.98 & 1.06 to 3.68 & 0.032 \\
\hline \multicolumn{4}{|c|}{ 1-month landmark analysis } \\
\hline $\begin{array}{l}\text { Non-diabetics } \\
(n=2147)\end{array}$ & $1^{*}$ & - & - \\
\hline $\begin{array}{l}\text { Good-control diabetics }{ }^{1} \\
(\mathrm{n}=295)\end{array}$ & 2.02 & 0.80 to 5.09 & 0.136 \\
\hline $\begin{array}{l}\text { Poor-control diabetics }{ }^{2} \\
(n=402)\end{array}$ & 3.25 & 1.57 to 6.71 & 0.001 \\
\hline \multicolumn{4}{|c|}{ 6-month landmark analysis } \\
\hline $\begin{array}{l}\text { Non-diabetics } \\
(n=2133)\end{array}$ & $1^{*}$ & - & - \\
\hline $\begin{array}{l}\text { Good-control diabetics }{ }^{1} \\
(\mathrm{n}=256)\end{array}$ & 1.40 & 0.60 to 7.90 & 0.236 \\
\hline $\begin{array}{l}\text { Poor-control diabetics }{ }^{2} \\
(n=430)\end{array}$ & 4.10 & 1.04 to 7.81 & 0.043 \\
\hline
\end{tabular}

*Reference group.

${ }^{1}$ Diabetic patient with $\mathrm{HbA} 1 \mathrm{c} \leq 7 \%$.

${ }^{2}$ Diabetic patient with $\mathrm{HbA} 1 \mathrm{c}>7 \%$. in uncontrolled diabetic patients [19-23]. Among studies two previous investigators $[19,20]$ examined the effect of glycaemic control on need for TVR in diabetic patients undergoing elective PCI. They observed lower rates of TVR, cardiac rehospitalization and recurrent angina in optimally-controlled ( $\mathrm{HbA} 1 \mathrm{c} \leq 7 \%)$ diabetic patients. comparable rates of adverse events in optimally-controlled diabetics and non-diabetics were also observed. A historical cohort study on 206 diabetic patients with drug-eluting stent implantation showed that pre-procedural HbA1c level is an independent predictor of MACE [21]. It is also demonstrated that a $\mathrm{HbA} 1 \mathrm{c}$ concentration of $6 \%$ to $7 \%$ is associated with a significantly higher risk of MACEs, TVR, and cardiovascular mortality following elective PCI in nondiabetic patients [24].

However, conflicting findings exist on the impacts of intensive glucose control with aggressive HbA1c goals on cardiovascular events [25-27]. In a 2-year follow-up study [28], the incidence of cardiovascular events was statistically similarly increased after acute myocardial infarction (AMI) in known diabetics and newly diagnosed diabetics compared with non-diabetic patients including IGT patients. However, when baseline characteristics were compared between the two groups, the level of HbA1c of newly diagnosed diabetics was significantly lower than that of known diabetic group $(5.7 \pm 0.4 \mathrm{mg} /$ $\mathrm{dL}$ vs. $8.1 \pm 1.5 \mathrm{mg} / \mathrm{dL}, \mathrm{p}<0.05)$. There are several previously published studies reporting that pre-procedural $\mathrm{HbA1c}$ levels are not predictive of cardiovascular events in diabetic patients following successful PCI [29-33]. In a recently published study on 952 diabetic patients 
undergoing PCI with stent implantation, no significant relationship was observed between pre-procedural HbA1c levels and patients' outcome[33]. The investigators attributed such conflicting finding, at least in part, to high rate of drug-eluting stent use in their study (70\%). The use of drug-eluting stent in our study (about 66\% in diabetic patients and $53 \%$ in non-diabetics) was similar to that study [33]; however, we observed that pre- and postprocedural glycaemic control predicts MACE following PCI even after adjustment for potential confounding effect of drug-eluting stent implantation.

Observational data relating uncontrolled diabetes to higher rates of cardiovascular events in this group of patients encouraged the researchers to assess the effect of therapies that improve glycemic control on cardiovascular risk. Clinical trials have already demonstrated that therapies that improve glycemic control decrease the risk of microvascular disease, including retinopathy, nephropathy, and neuropathy [34]. However, trials attempting to decrease macrovascular events have been unsuccessful; in the Action to Control Cardiovascular Risk in Diabetes (ACCORD) [35], Action in Diabetes and Vascular Disease: Preterax and Diamicron Modified Release Controlled Evaluation (ADVANCE) [36], and Veterans Affairs Diabetes Trial (VADT) studies [37], improved glycemic control showed no reduction in the rate of cardiovascular events and in ACCORD trial [35], even it was associated with increased risks of death from any cause and death from cardiovascular events.

Ike and colleagues [38] have recently published a study on the effect of glycaemic control after PCI in patients with pre-procedural uncontrolled diabetes $(\mathrm{HbA1c} \geq 6.9)$ and observed that glycemic control started at PCI and continued afterwards for approximately 300 days was not associated with improved clinical MACE at follow-up. The authors suggested that a so-called "metabolic memory (legacy) effect" which is a complex of MACE-increasing factors due to chronic hyperglycaemia might have adversely affected the clinical outcome in all diabetic patients with pre- procedural impaired glycaemic control irrespective of their post-procedural glycaemic control. However, this study was not a prospective cohort study and one cannot exclude the possibility that the clinical outcome may have been influenced for this reason.

The higher rates of MACE in diabetic patients with worse glycaemic control may have several explanations: There is evidence that chronic hyperglycemia induces vascular endothelial cell damage, with resultant vasomotor dysfunction, excessive extracellular matrix formation, and increased cellular proliferation. Hyperinsulinemia has been widely proposed as a predisposing factor for stent restenosis in diabetic patients [39], and concerns have been raised over the management of diabetes with exogenously administered insulin, as it may accelerate progression of
CAD through its atherogenic mechanisms [40, 41]. Currently data regarding the impact of insulin therapy on restenosis after PCI are controversial [42-44]. While Abizaid et al. [45] found an increased rate of TLR in insulin-treated diabetic patients compared with non-diabetic patients, others $[46,47]$ demonstrated no significant difference in restenosis rates between the two groups. In our study there was no difference between the insulin-treated and noninsulin-treated diabetics with respect to TVR and MACE, and in multivariate Cox regression analysis insulin usage was not an independent predictor for MACE.

The novel aspect of our study was that in addition to pre-procedural HbA1c levels, we measured the postprocedural circulating $\mathrm{HbA} 1 \mathrm{c}$ concentrations at 1 and 6 months after PCI. Hence, it not only reflects the ambient glycaemic control 2-3 months before procedure, but also surrogates the post-procedural glycaemic control in the first six months after PCI.

It is also notable that in this study we observed that current cigarette smoking and WC were tended to be predictors for better PCI outcome. Current smoking showed a protective effect on outcome of PCI in univariable analysis but it was not found to be an independent predictor for outcome after controlling for other covariates (Adjusted HR: 0.60, 95\% CI: 0.35 to $1.03, \mathrm{p}=0.07$ ). Waist circumference however showed statistically significant and independent protective effect on outcome of PCI in multivariable model. Although we don't know the exact reason of such observation in our study, there is conflicting data regarding the effect of obesity on outcome of PCI [48], and a more optimal medical treatment in the obese group could explain the observed better outcome ("obesity paradox") in these patients [49].

\section{Limitations}

There are several potential limitations in our study that needs to be mentioned. First, in this study routine angiographic follow-up was not performed, and thus absolute restenosis rates could not be reported. Second, this was a single-center experience and larger multi-center studies should confirm our findings. Finally, although our method of assessment, protocol for calibrating HbA1c levels, and guidelines of reporting ensures high accuracy, HbA1c measurement error might be still a concern especially because this index was not derived from repeated measurements over time.

\section{Conclusions}

In conclusion, these data suggest that good glycaemic control to obtain HbA1c levels $\leq 7 \%$ in diabetic patients undergoing coronary artery stenting may be beneficial in reducing the risk of restenosis and in improvement of the clinical outcome after PCI at 1-year follow-up. 


\section{Competing interests}

The authors declare that they have no competing interests.

\section{Authors' contributions}

SEK participated in study design, have revisited critically the manuscript for important intellectual content, and given final approval of the version to be published. MAB, MS, MRM, HP, SS, NR, MA, EH, and EN have made substantial contributions to conception and design, or acquisition of data, or analysis and interpretation of data. SS participated in the design of the study and supervised the statistical analysis. FM performed the statistical analysis and involved in drafting the manuscript. HG participated in study design and coordination and helped to draft the manuscript. All authors read and approved the final manuscript.

\section{Acknowledgements}

The authors acknowledge financial support from Research council of the Tehran University of Medical Sciences. Our thanks are also due to Dr Feizi I. for his major contribution to data collection.

\section{Author details}

'Department of Cardiology, Tehran Heart Center, Tehran University of Medical Sciences, Tehran, Iran. ${ }^{2}$ Research Department, Tehran Heart Center, Tehran University of Medical Sciences, Tehran, Iran. ${ }^{3}$ Department of Clinical and Surgical Pathology, Tehran Heart Center, Tehran University of Medical Sciences, Tehran, Iran. 'Students' Scientific Research Center (SSRC), Tehran University of Medical Sciences, Tehran, Iran. ${ }^{5}$ Endocrinology and Metabolism Research Center (EMRC), Shariati Hospital, Tehran University of Medical Sciences, Tehran, Iran. ${ }^{6}$ Sina Trauma Research Center,Tehran University of Medical Sciences, Tehran, Iran. ${ }^{7}$ Tehran Heart Center, 1411713138, Karegar Shomali St., Jalal al-Ahmad Cross, Tehran, Iran.

Received: 11 April 2012 Accepted: 1 July 2012

Published: 17 July 2012

\section{References}

1. Prevention of diabetes mellitus. Report of a WHO study group. World Health Organ Tech Rep Ser 1994, 844:1-100.

2. Cutlip DE, Chhabra AG, Baim DS, Chauhan MS, Marulkar S, Massaro J, Bakhai A, Cohen DJ, Kuntz RE, Ho KK: Beyond restenosis: five-year clinical outcomes from second-generation coronary stent trials. Circulation 2004, 110:1226-1230.

3. Flaherty JD, Davidson CJ: Diabetes and coronary revascularization. JAMA 2005, 293:1501-1508.

4. Lee TT, Feinberg L, Baim DS, Holmes DR, Aroesty JM, Carrozza JP Jr, Cohen DJ, Ho KK, Cutlip DE: Effect of diabetes mellitus on five-year clinical outcomes after single-vessel coronary stenting (a pooled analysis of coronary stent clinical trials). Am J Cardiol 2006, 98:718-721.

5. Ruygrok PN, Webster MW, de Valk V, van Es GA, Ormiston JA, Morel MA, Serruys PW: Clinical and angiographic factors associated with asymptomatic restenosis after percutaneous coronary intervention. Circulation 2001, 104:2289-2294.

6. Stettler C, Allemann S, Egger M, Windecker S, Meier B, Diem P: Efficacy of drug eluting stents in patients with and without diabetes mellitus: indirect comparison of controlled trials. Heart 2006, 92:650-657.

7. Stettler C, Allemann S, Wandel S, Kastrati A, Morice MC, Schomig A, Pfisterer ME, Stone GW, Leon MB, de Lezo JS, et al: Drug eluting and bare metal stents in people with and without diabetes: collaborative network metaanalysis. BMJ 2008, 337:a1331.

8. Kapur A, Hall RJ, Malik IS, Qureshi AC, Butts J, de Belder M, Baumbach A, Angelini G, de Belder A, Oldroyd KG, et al: Randomized comparison of percutaneous coronary intervention with coronary artery bypass grafting in diabetic patients. 1-year results of the CARDia (Coronary Artery Revascularization in Diabetes) trial. J Am Coll Cardiol 2010, 55:432-440.

9. Dauerman HL: Percutaneous coronary intervention, diabetes mellitus, and death. J Am Coll Cardiol 2010, 55:1076-1079.

10. Takara A, Ogawa H, Endoh Y, Mori F, Yamaguchi J, Takagi A, Koyanagi R, Shiga T, Kasanuki H, Hagiwara N: Long-term prognosis of diabetic patients with acute myocardial infarction in the era of acute revascularization. Cardiovasc Diabetol 2010, 9:1

11. Kornowski R, Mintz GS, Kent KM, Pichard AD, Satler LF, Bucher TA, Hong MK, Popma JJ, Leon MB: Increased restenosis in diabetes mellitus after coronary interventions is due to exaggerated intimal hyperplasia. A serial intravascular ultrasound study. Circulation 1997, 95:1366-1369.

12. Dunn PJ, Cole RA, Soeldner JS, Gleason RE: Reproducibility of hemoglobin Alc and sensitivity to various degrees of glucose intolerance. Ann Intern Med 1979, 91:390-396.

13. Nathan DM, Singer DE, Hurxthal K, Goodson JD: The clinical information value of the glycosylated hemoglobin assay. N Engl J Med 1984, 310:341-346.

14. Stamler J, Vaccaro O, Neaton JD, Wentworth D: Diabetes, other risk factors, and 12-yr cardiovascular mortality for men screened in the Multiple Risk Factor Intervention Trial. Diabetes Care 1993, 16:434-444.

15. Dafni U: Landmark analysis at the 25 -year landmark point. Circ CardiovasC Qual Outcomes 2011, 4:363-371.

16. Indolfi C, Esposito G, Stabile E, Cavuto L, Pisani A, Coppola C, Torella D, Perrino C, Di Lorenzo E, Curcio A, et al: A new rat model of small vessel stenting. Basic Res Cardiol 2000, 95:179-185

17. Bennett MR: In-stent stenosis: pathology and implications for the development of drug eluting stents. Heart 2003, 89:218-224.

18. Indolfi C, Torella D, Cavuto L, Davalli AM, Coppola C, Esposito G, Carriero MV, Rapacciuolo A, Di Lorenzo E, Stabile E, et al: Effects of balloon injury on neointimal hyperplasia in streptozotocin-induced diabetes and in hyperinsulinemic nondiabetic pancreatic islet-transplanted rats. Circulation 2001, 103:2980-2986.

19. Corpus RA, George PB, House JA, Dixon SR, Ajluni SC, Devlin WH, Timmis GC, Balasubramaniam M, O'Neill WW: Optimal glycemic control is associated with a lower rate of target vessel revascularization in treated type II diabetic patients undergoing elective percutaneous coronary intervention. J Am Coll Cardiol 2004, 43:8-14.

20. Briguori C, Condorelli G, Airoldi F, Mikhail GW, Ricciardelli B, Colombo A: Impact of glycaemic and lipid control on outcome after percutaneous coronary interventions in diabetic patients. Heart 2004, 90:1481-1482.

21. Ueda H, Mitsusada N, Harimoto K, Miyawaki M, Yasuga Y, Hiraoka H: Glycosylated hemoglobin is a predictor of major adverse cardiac events after drug-eluting stent implantation in patients with diabetes mellitus. Cardiology 2010, 116:51-57.

22. Kasai T, Miyauchi K, Kajimoto K, Kubota N, Kurata T, Daida H: Influence of diabetes on $>10$-year outcomes after percutaneous coronary intervention. Hear Vessel 2008, 23:149-154.

23. Cicek G, Uyarel H, Ergelen M, Ayhan E, Abanonu GB, Eren M, Gibson CM: Hemoglobin A1c as a prognostic marker in patients undergoing primary angioplasty for acute myocardial infarction. Coron Artery Dis 2011, 22:131-137.

24. Corpus RA, O'Neill WW, Dixon SR, Timmis GC, Devlin WH: Relation of hemoglobin A1c to rate of major adverse cardiac events in nondiabetic patients undergoing percutaneous coronary revascularization. Am J Cardiol 2003, 92:1282-1286.

25. Cefalu WT: Glycemic targets and cardiovascular disease. N Engl J Med 2008, 358:2633-2635.

26. Kurukulasuriya LR, Sowers JR: Therapies for type 2 diabetes: lowering $\mathrm{HbA1c}$ and associated cardiovascular risk factors. Cardiovasc Diabetol 2010, 9:45.

27. Liu Y, Yang YM, Zhu J, Tan HQ, Liang Y, Li JD: Prognostic significance of hemoglobin A1c level in patients hospitalized with coronary artery disease. A systematic review and meta-analysis. Cardiovasc Diabetol 2011, 10:98.

28. Kitada S, Otsuka Y, Kokubu N, Kasahara Y, Kataoka Y, Noguchi T, Goto Y, Kimura G, Nonogi H: Post-load hyperglycemia as an important predictor of long-term adverse cardiac events after acute myocardial infarction: a scientific study. Cardiovasc Diabetol 2010, 9:75.

29. Hasdai D, Rizza RA, Grill DE, Scott CG, Garratt KN, Holmes DR Jr: Glycemic control and outcome of diabetic patients after successful percutaneous coronary revascularization. Am Heart J 2001, 141:117-123.

30. Kauffman AB, Delate T, Olson KL, Cymbala AA, Hutka KA, Kasten SL, Rasmussen JR: Relationship between haemoglobin A1C values and recurrent cardiac events: a retrospective, longitudinal cohort study. Clin Drug Investig 2008, 28:501-507.

31. Lindsay J, Sharma AK, Canos D, Nandalur M, Pinnow E, Apple S, Ruotolo G, Wijetunga M, Waksman R: Preprocedure hyperglycemia is more strongly associated with restenosis in diabetic patients after percutaneous coronary intervention than is hemoglobin A1C. Cardiovasc Revasc Med 2007, 8:15-20

32. O'Sullivan CJ, Hynes N, Mahendran B, Andrews EJ, Avalos G, Tawfik S, Lowery A, Sultan S: Haemoglobin A1c ( $\mathrm{HbA1C})$ in non-diabetic and 
diabetic vascular patients. Is $\mathrm{HbA} 1 \mathrm{C}$ an independent risk factor and predictor of adverse outcome? Eur J Vasc Endovasc Surg 2006, 32:188-197.

33. Lemesle G, Bonello L, de Labriolle A, Maluenda G, Syed Al, Collins SD, BenDor I, Torguson R, Kaneshige K, Xue Z, et al: Prognostic value of hemoglobin A1C levels in patients with diabetes mellitus undergoing percutaneous coronary intervention with stent implantation. Am J Cardiol 2009, 104:41-45

34. : Intensive blood-glucose control with sulphonylureas or insulin compared with conventional treatment and risk of complications in patients with type 2 diabetes (UKPDS 33). UK Prospective Diabetes Study (UKPDS) Group. Lancet 1998, 352:837-853.

35. Gerstein HC, Miller ME, Byington RP, Goff DC Jr, Bigger JT, Buse JB, Cushman WC, Genuth S, Ismail-Beigi F, Grimm RH Jr, et al: Effects of intensive glucose lowering in type 2 diabetes. N Engl J Med 2008, 358:2545-2559.

36. Patel A, MacMahon S, Chalmers J, Neal B, Billot L, Woodward M, Marre M, Cooper M, Glasziou P, Grobbee D, et al: Intensive blood glucose control and vascular outcomes in patients with type 2 diabetes. N Engl I Med 2008, 358:2560-2572.

37. Duckworth W, Abraira C, Moritz T, Reda D, Emanuele N, Reaven PD, Zieve FJ, Marks J, Davis SN, Hayward R, et al: Glucose control and vascular complications in veterans with type 2 diabetes. N Engl J Med 2009, 360:129-139.

38. Ike A, Nishikawa H, Shirai K, Mori K, Kuwano T, Fukuda Y, Takamiya Y, Yanagi D, Kubota K, Tsuchiya Y, et al: Impact of glycemic control on the clinical outcome in diabetic patients with percutaneous coronary interventionfrom the FU-registry. Circ J 2011, 75:791-799.

39. Marso SP, Mak KH, Topol EJ: Diabetes mellitus: biological determinants of atherosclerosis and restenosis. Semin Interv Cardiol 1999, 4:129-143.

40. Genuth S: Exogenous insulin administration and cardiovascular risk in non-insulin-dependent and insulin-dependent diabetes mellitus. Ann Intern Med 1996, 124:104-109.

41. Feinglos MN, Bethel MA: Therapy of type 2 diabetes, cardiovascular death, and the UGDP. Am Heart J 1999, 138:S346-S352.

42. Malmberg K, Ryden L, Efendic S, Herlitz J, Nicol P, Waldenstrom A, Wedel H, Welin L: Randomized trial of insulin-glucose infusion followed by subcutaneous insulin treatment in diabetic patients with acute myocardial infarction (DIGAMI study): effects on mortality at 1 year. J Am Coll Cardiol 1995, 26:57-65.

43. Malmberg K, Ryden L, Wedel H, Birkeland K, Bootsma A, Dickstein K, Efendic S, Fisher M, Hamsten A, Herlitz J, et al: Intense metabolic control by means of insulin in patients with diabetes mellitus and acute myocardial infarction (DIGAMI 2): effects on mortality and morbidity. Eur Heart J 2005, 26:650-661.

44. Van den Berghe G, Wouters PJ, Bouillon R, Weekers F, Verwaest C, Schetz M, Vlasselaers $D$, Ferdinande $P$, Lauwers $P$ : Outcome benefit of intensive insulin therapy in the critically ill: insulin dose versus glycemic control. Crit Care Med 2003, 31:359-366.

45. Abizaid A, Kornowski R, Mintz GS, Hong MK, Abizaid AS, Mehran R, Pichard $A D$, Kent KM, Satler LF, Wu H, et al: The influence of diabetes mellitus on acute and late clinical outcomes following coronary stent implantation. J Am Coll Cardiol 1998, 32:584-589.

46. Schofer J, Schluter M, Rau T, Hammer F, Haag N, Mathey DG: Influence of treatment modality on angiographic outcome after coronary stenting in diabetic patients: a controlled study. J Am Coll Cardiol 2000, 35:1554-1559.

47. Hage C, Norhammar A, Grip L, Malmberg K, Sarkar N, Svane B, Ryden L: Glycaemic control and restenosis after percutaneous coronary interventions in patients with diabetes mellitus: a report from the Insulin Diabetes Angioplasty study. Diab Vasc Dis Res 2009, 6:71-79.

48. Ndrepepa G, Keta D, Byrne RA, Schulz S, Mehilli J, Seyfarth M, Schomig A Kastrati A: Impact of body mass index on clinical outcome in patients with acute coronary syndromes treated with percutaneous coronary intervention. Hear Vessel 2010, 25:27-34.

49. Schenkeveld L, Magro M, Oemrawsingh RM, Lenzen M, de Jaegere $P$, van Geuns RJ, Serruys PW, van Domburg RT: The influence of optimal medical treatment on the 'obesity paradox', body mass index and long-term mortality in patients treated with percutaneous coronary intervention: a prospective cohort study. BMJ Open 2012, 2:e000535.

doi:10.1186/1475-2840-11-82

Cite this article as: Kassaian et al:: Glycosylated hemoglobin (HbA1c)

levels and clinical outcomes in diabetic patients following coronary artery stenting. Cardiovascular Diabetology 2012 11:82.

\section{Submit your next manuscript to BioMed Central and take full advantage of:}

- Convenient online submission

- Thorough peer review

- No space constraints or color figure charges

- Immediate publication on acceptance

- Inclusion in PubMed, CAS, Scopus and Google Scholar

- Research which is freely available for redistribution 